\title{
ALCOLEA DEL CAMPO X MADRID: \\ ANDRÉS HURTADO Y EL ESPACIO SOCIAL EN LA OBRA \\ “EL ÁRBOL DE LA CIENCIA” DE PÍO BAROJA
}

Gustavo Costa*

RESUMEN: El árbol de la ciencia es una obra publicada por Pío Baroja en 1911. Esta investigación tiene como objetivo comparar y contrastar el espacio urbano de la capital Madrid con el espacio rural en Alcolea del Campo a través del texto literario de Baroja y de su protagonista: Andrés Hurtado. A través de la teoría urbana de Henri Lefebvre y de la teoría sobre el campo y la ciudad de Raymond Williams, se abordarán en este ensayo perspectivas culturales, representaciones paisajísticas y sociales que son fundamentales para nuestro análisis de estilo y de la obra como arte. Se notará que la ciudad es para Andrés Hurtado un ambiente lleno de vida, donde lo urbano le produce placer, mientras que el pueblo le parece aburrido debido a la monótona actuación de los individuos que allí residen. Se involucrará igualmente el paisaje como parte de estos espacios, sean estos espacios de placer o de desconsuelo.

PALABRAS-CLAVE: Espacio Social; Existencialismo; Literatura Española; Pío Baroja

* Doutorando em Espanhol (Literatura Latino-americana) pela Texas Tech University (TTU). Professor de Espanhol e Língua Portuguesa na mesma instituição para alunos de graduação. 


\section{I- Introducción}

El monótono golpeteo del tren acompañaba el soliloquio interior de Andrés; se vieron a lo lejos varias veces las luces de Madrid en medio del campo, pasaron tres o cuatro estaciones desiertas y entró el revisor... (BAROJA, 1911, p. 184)

En el inicio del siglo XX en España se daba a conocer lo que se consideraba la "transformación urbana" debido al cambio de siglo y la modernidad que surgía en las grandes metrópolis europeas. Esta investigación tiene como objetivo analizar, a través del personaje Andrés Hurtado, su estilo de vida en la ciudad de Madrid en contraste al pueblo de Alcolea del Campo por medio del espacio, que es fundamental para conocernos el ámbito donde el protagonista vive, trabaja, se divierte y se aburre. El paisaje sea urbano sea rural nos muestra cómo son diferentes las percepciones que tiene un individuo real dependiendo del sitio donde se encuentre. Analizaremos, por medio de la teoría del espacio de Lefebvre, los diferentes tipos de espacios (percibido, concebido y vivido) y analizaré la construcción de estos espacios de Baroja. El campo es visto tanto en el mundo real como literario como el entorno de personas y lugares sencillos donde uno encuentra la tranquilidad, mientras que la ciudad es observada como el lugar de luminosidad y de relaciones sociales. Además, en el centro urbano uno se encuentra con el bullicio, la profanidad, a la vez que en el campo se presenta la incultura y las restricciones. Según Williams "Clearly the contrast of country and city is one of the major forms in which we become conscious of a central part of our experience and of the crisis of our society" (289). Consecuentemente, conectaremos esta experiencia y crisis en el paradigma campo-ciudad a través del personaje Andrés Hurtado.

\section{II- El espacio urbano: Andrés Hurtado en Madrid}

The city, no less, has been of many kinds: state capital, administrative base, religious centre, market-town, port and mercantile depot, military barracks, industrial concentration [...] (WILLIAMS, 1973, p. 1).

El árbol de la ciencia de Pío Baroja es una novela autobiográfica y es parte de una trilogía titulada "La raza". Los personajes principales son Andrés Hurtado y su tío Iturrioz. 
Con el tío habla sobre diferentes temas, desde política hasta su vida amorosa. Igualmente, tiene algunos amigos como Julio Aracil y Montaner, ambos eran amigos de Baroja en la vida real, además de una novia llamada Lulú. El autor narra el espacio donde vivió partes de su vida, sea en Madrid o en el pueblo, refiriéndose a los problemas políticos, a las enfermedades y a la falta de recursos de la población en inicios del siglo XX. Andrés Hurtado tiene una hermana, otro hermano pequeño que está enfermo Don Pedro Hurtado, su padre, con quien tiene muchas diferencias, principalmente porque Pedro era de derecha y no sentía mucho afecto por su propio hijo. Con la muerte de Luisito, así como la muerte del hermano de Pío, Darío Baroja, el autor protagonista emprende un viaje con la intención de descubrir el sentido de la vida.

Empezaremos este estudio exponiendo la vida del personaje literario Andrés Hurtado en Madrid. Fue un estudiante en el instituto en la capital. Además de tener contacto con sus compañeros en este ámbito estudiantil, no deja de disfrutar de la ciudad. Frecuentaba cafés, a y en algunas ocasiones, Andrés solía entrar en los cafés cantantes y en casas de juego, espacios que compartía con su amigo Fermín Ibarra "Hurtado le contaba lo que hacía, le hablaba de la clase de disección de los cafés cantantes, de la vida de Madrid de noche” (BAROJA, 1911, pp. 59; 60). El Café del Siglo era este sitio donde el protagonista solía frecuentar más a menudo. De acuerdo con Bonet "El café es un lugar de reunión y de encuentro, de conversación e intercambio social. Es un espacio público y ciudadano" (apud MARTÍN, 2014, p. 14). Por tanto, no es considerado solamente un espacio de comercio, sino también social, un sitio de encuentros donde el protagonista se juntaba con amigos. Allí se divertía, era un lugar de comunicación e incertidumbres, dado que por ser el Café un lugar de comunicación no sabemos exactamente cuánto tiempo uno permanecerá allí.

Según Lefebvre "El espacio es mucho más que un mero escenario, receptáculo pasivo, de la realidad social [...] el espacio se convierte en un ámbito privilegiado para la interacción social [...]" (EZQUERRA, 2014, p. 122). Andrés Hurtado, por ello, participa activamente de lo que este ambiente urbano le proporciona, siendo la interacción humana 
parte de este espacio social. Nos conviene, consiguientemente, definir el concepto de espacio

El espacio es un producto social, fruto de las determinadas relaciones de producción que se están dando en un momento dado, así como el resultado de la acumulación de un proceso histórico que se materializa en una determinada forma espacio-territorial. (123)

Se nota, por ende, que Andrés Hurtado es parte activa del grupo social a que pertenece. El personaje, a la vez, se aísla, por ejemplo, cuando está en su casa, más precisamente en su cuarto, donde mira lo exterior a través de la ventana "Esta ventana caía sobre la parte de atrás de varias casas de las calles de Santa Isabel y de la Esperancilla, y sobre unos patios y tejavanas" (Baroja 49). La ventana simboliza la conexión entre el mundo interior y exterior del protagonista, funcionando como un puente donde el que está adentro logra visualizar lo que está afuera, sea la calle, las casas, el comercio. Sin embargo, necesita cruzar este puente. La ventana “indica la fórmula de cómo se capta las intensidades del ambiente - sea del otro, sea del exterior, sea del real, como se prefiera nombrar este gesto simultáneo de estar en sí y en el mismo mundo" (Gomes 167). Estas imágenes exteriores, desde la perspectiva interna del protagonista nos proporciona una descripción del espacio urbano de la ciudad de Madrid debido a los nombres de las calles mencionadas. Pío Baroja considera fundamental describir el espacio donde los personajes circulan "El autor muestra dónde viven y en qué ambiente se mueven porque si no, no podría hablar de ellos" (BAROJA, 1983, p. 455). Por lo tanto, si no hay un espacio no hay como crear una historia en donde pueden actuar sus personajes.

Para Baroja, el espacio exterior es más contemplado que el interior. Algunos círculos que Andrés Hurtado frecuenta en la capital, como ya mencionado anteriormente, son los cafés. Igualmente, debido a su carrera, visita algunos espacios públicos, como un hospital. A seguir tenemos la descripción del hospital San Juan de Dios

El hospital aquel, ya derruido por fortuna, era un edificio inmundo [...] las ventanas de las salas daban a la calle Atocha y tenían, además de las rejas, unas alambreras para que las mujeres recluidas no se asomaran y escandalizaran [...] (BAROJA, 1911, p. 79). 
Se percibe que, sea en un café o en un hospital, los movimientos del personaje en el ámbito urbano exponen sus hábitos y tradiciones de acuerdo con el ambiente donde está insertado. De acuerdo con Balzac "los tipos de Baroja son resultado del clima, del medio, de las costumbres, pero también del azar" (apud ZWEIG, 2004, p. 25). Así, Andrés Hurtado puede ser considerado como un producto de su medio debido a su interacción con los individuos de este determinado espacio social

Este es, para Lefebvre, el principal secreto del espacio de cada sociedad y está directamente relacionado con la percepción que la gente tiene de él con respecto a su uso cotidiano: sus rutas de paseo, los lugares de encuentro.... (EZQUERRA, 2014, p. 124).

Por ende, el espacio social proporciona al protagonista su propia identidad con relación a sus gustos por la vida citadina, principalmente relacionado a este intercambio social en estos "lugares de encuentro" en la Madrid urbana. Notamos, igualmente, la experiencia del protagonista en Madrid luego de regresar de Alcolea del Campo, proporcionándonos más detalles del espacio social en cuestión.

Andrés Hurtado regresa a Madrid en medio del caos en el país, dado que España iba a declarar la guerra hacia los Estados Unidos. Percibía, por tanto, la confusa agitación en el espacio urbano de la capital española "Había alborotos, manifestaciones en las calles, música patriótica a todo pasto" (BAROJA, 1911, p. 235). Al no lograr un trabajo a su llegada a la ciudad, se sentía libre para gozar la ciudad. Solía estar en la Biblioteca Nacional en el período de la mañana, a caminar por las calles por la tarde y por la noche, además de juntarse con amigos. Se nombran calles por donde transitaban, como la calle de Alcalá, así como esquinas, por ejemplo, la de Peligros, sin mencionar a los famosos cafés, como el de Fornos (241). Muchos eventos ocurrían en las calles del país en el siglo XX, era la realidad citadina en pleno desarrollo. La ciudad es sinónimo de vida. De acuerdo con Williams "There was a new kind of pleasure, a new enlargement of identity, in what he (Baudeleire) called bathing oneself in the crowd" (1973, p. 234), es decir, el placer que la metrópolis proporcionaba a nuestro protagonista le ubicó en el espacio social "percibido" de acuerdo 
con la teoría de Lefebvre, siendo este el espacio de interacción, de encuentro. En la obra analizada, hay diversas imágenes con relación a su vida en el espacio exterior, su contacto con la gente. Con su amigo Julio va al barrio de Salamanca (BAROJA, 1911, p. 244), al transitar por la calle encuentra a amigos, como a Fermín Ibarra (247), por ende, la calle es un lugar de encuentro. La experiencia urbana de Hurtado en las calles de Madrid puede ser considerada la representación de la rutina del personaje en la metrópolis donde suele encontrar a los amigos, a la novia, por lo tanto, el espacio de tránsito para llegar a los distintos puntos de la misma ciudad, como a los cafés, a la casa de prostitución o a la tienda de su novia Lulú. La necesidad y el placer se mezclan con la vida citadina del personaje, lo que hace con que su experiencia en la urbe le sea no solo conveniente, sino también complaciente.

Siguiendo con la tríade espacial propuesta por Lefebvre, nos presenta el "espacio vivido"

Es el espacio experimentado directamente por sus habitantes y usuarios a través de una compleja amalgama de símbolos e imágenes [...] Este es también un espacio evasivo ya que la imaginación humana busca cambiarlo y apropiarlo (apud EZQUERRA, 2014, p. 124).

Se perciben los siguientes símbolos e imágenes presentes en la ciudad de Madrid: la trivialidad intelectual en las universidades de Madrid, como poder ver en la universidad donde estudió Andrés; la impasibilidad de los políticos; los ámbitos de prostitución; la condición de los hospitales y su falta de higienización, Por ende, estos problemas sociales simbolizan la sociedad española del inicio del siglo XX por medio de una crisis social urbano.

En el entorno urbano es que podemos hacer una conexión entre el protagonista y la figura del flâneur"1. De acuerdo con la teoría de Baudelaire, el flâneur es aquel que suele caminar por la ciudad con el objetivo de experimentarla. La palabra tiene origen en el verbo

\footnotetext{
${ }^{1} \mathrm{O}$ flanêur [...] é o leitor da cidade, bem como de seus habitantes, através de cujas faces tenta decifrar os sentidos da vida urbana. De fato, através de suas andanças, ele transforma a cidade em um espaço para ser lido, um objeto de investigação, uma floresta de signos a serem decodificados - em suma, um texto" (apud MASSAGLI, 2015, p. $57)$.
} 
francés "Flâner", que significa "vagabundear". El flâneur ama las calles, percibe en los detalles lo que para otros ciudadanos pasan desapercibido. Según Simmel "La mentalidad psicología del individuo moderno que habita las grandes ciudades europeas se caracteriza fundamentalmente por lo que él llama el "acrecentamiento de la vida nerviosa” (apud García, 2013, p. 2). Por ende, el hecho de vivir en la urbe hace con que la vida del protagonista sea más activa, dinámica, donde la interacción social tiene una representación significativa en la vida de los habitantes en un espacio donde el individuo necesita acompañar su velocidad y, es lo que Hurtado se propone a hacer a través de su estilo de vida, de los espacios sociales que la ciudad le proporciona mediante su "flânerie", es decir, por medio de sus recorridos por la capital española, observando a los detalles de los espacios de Madrid, sean sociales, políticos o incluso de la misma calle.

\section{III - El espacio rural: Andrés Hurtado en Alcolea del Campo}

Clearly the contrast of country and city is one of the major forms in which we become conscious of a central part of our experience and of the crises of our society (WILLIAMS, 1973, p. 289).

Anteriormente, analizamos el entorno social urbano donde el protagonista Andrés Hurtado estaba insertado. A partir de ahora, enfocaremos en la experiencia del personaje en el espacio rural, en el pueblo de Alcolea del Campo, sitio este que se contrasta a la capital, donde la vida urbana le proporciona a Hurtado momentos de interacción con sus amigos en los que llamamos de espacios de encuentros.

La experiencia rural del personaje empieza con su llegada al pueblo. En la calle hacía mucho calor "Al salir a la calle, la misma bofetada de calor le sorprendió a Andrés" (Baroja 188), siendo el clima la primera sorpresa que tiene en su nueva población. En seguida, sale a dar una vuelta en el pueblo junto al secretario y el médico

Seguía aquel calor exasperante, aquel aire inflamado y seco. Pasaron por la plaza, con su iglesia llena de añadidos y composturas, y sus puestos de cosas de hierro y esparto. Siguieron por una calle 
ancha, de caserones blancos, con su balcón central lleno de geranios, y su reja, afiligranada, con una cruz de Calatrava en lo alto (BAROJA, 1911, p. 189).

Se percibe, por ende, en esta descripción, imágenes comunes de un pueblo: una plaza y la iglesia, casas con plantas a la vista y símbolos religiosos, como cruces en estas mismas casas. Por la noche, salía Andrés a la calle y sentía que era un lugar utópico. Las luces le proporcionaban al paisaje un tono melancólico "caía una guirnalda de hiedra negra, y todo este pueblo, grande, desierto, silencioso, bañado por la suave claridad de la luna, parecía un inmenso sepulcro" (191), tomándose como negativo sus impresiones tanto del día como de la noche en este espacio campestre.

Baroja, por medio del personaje Andrés Hurtado, describe la España rural del fin del siglo XIX. Menciona que los hábitos de la localidad eran exageradamente españoles (apud GARCÍA, 2013, p. 7). Mientras en la ciudad se observaba la vida social del personaje, en el campo esta vida social era mínima. Hurtado trabajaba por las mañanas y, por las tardes, se quedaba en la fonda. Por las noches "iba a pasear solo por las calles desiertas [...] ¡Qué tristeza! ¡Qué malestar físico le producía aquél ambiente! (BAROJA, 1911, p. 193). Se percibe, entonces, que la falta de personas en las calles, el lúgubre en este espacio solitario le produce desasosiego. Claro está que Andrés pasa por un momento de adaptación en el pueblo, dado que su ritmo de vida era completamente diferente en la ciudad, siendo Madrid el espacio de aglomeración, mientras el Alcolea del Campo es lo contrario y no hay vida social:

El pueblo no tenía el menor sentido social; las familias se metían en sus casas, como los trogloditas en su cueva. No había solidaridad; nadie sabía ni podía utilizar la fuerza de la asociación. Los hombres iban al trabajo y a veces al casino. Las mujeres no salían más que los domingos a misa. Por falta de instinto colectivo el pueblo se había arruinado (203).

Para el protagonista, no sólo era difícil aceptar este nuevo estilo de vida en el cual estaba involucrado, sino también comprender la individualidad y el aburrimiento de la localidad. Había una distancia entre las personas que allí vivían, un hueco en el espacio de 
convivencia, donde el aspecto social estaba prácticamente ausente. Andrés Hurtado cargaba un fuerte sentimiento citadino dentro de sí, proporcionándonos la idea de taedium vitae, es decir, una vida aburrida y melancólica. Según Spengler "El hombre de la urbe lleva eternamente consigo la ciudad [...] Ha perdido el campo en su interior y ya no puede encontrarlo fuera" (apud GARCÍA, 2013, p. 9).

Para nuestro protagonista, Alcolea del Campo era un mundo utópico. Su casa era su espacio de protección, ya que el pueblo le proporcionaba todo de lo negativo: el extremo calor, el silencio de las calles, incluso la propia gente local, a quienes él consideraba egoístas e envidiosos. Al llegar el invierno, ya no soportando quedarse en su casa, decidió frecuentar el casino del pueblo. Podemos comentar a esta idea el concepto de habitus por Bordieu "El habitus produce al individuo, le interioriza inconscientemente los valores y las reglas de la sociedad y del grupo social de pertenencia" (126). Consecuentemente, el sentimiento del protagonista en relación con su situación vivida en este espacio rural juntamente a sus opiniones y valores sobre la actuación y no identificación hacia los individuos del pueblo demuestra su manera de pensar y actuar en el espacio en donde está incluido, por tanto, no se encuentra en Alcolea del Campo un sentimiento de comunidad ${ }^{2}$.

Poco a poco la gente del pueblo empezó a criticarlo, lo que le tocó una mala reputación. Su casa era el espacio donde se evadía, en su cuarto leía sus libros y dejaba que el tiempo pasara "en aquel mausoleo blanqueado y silencioso" (BAROJA, 1911, p. 218). Podemos considerar la casa, de acuerdo con Lefebvre, como el espacio "vivido", dado que es un espacio de representación, que simboliza la protección del protagonista hacia el mundo exterior. No se considera el espacio de la casa como solamente un espacio físico, sino también un espacio de refugio, de expresión emotiva. Analicemos el simbolismo de la casa "En general, la casa expresa la estructura del habitar en sus aspectos físicos y psíquicos.

\footnotetext{
${ }^{2}$ De acuerdo con Mcmilan \& Chavez "El sentimiento de comunidad (SdC) se define como un sentimiento de pertenencia a una comunidad por parte de sus miembros. Estos miembros se preocupan unos con otros y con el grupo y existe una creencia compartida de que sus necesidades se satisfarán mediante el compromiso de permanecer juntos" (apud SILVA, 2015, p. 31, tradução nossa).
} 
Está pensada, o debe ser pensada, como un sistema de actividades concretizado como un espacio de lugares de carácter distintos (RODRIGUES, 2015, p. 21, tradução nossa). Por ende, el protagonista goza de la casa por ser su lugar seguro, donde no hay nadie que le pueda molestar, viviendo en su mundo interior que considera real mientras juzga absurdo el mundo exterior del pueblo. Llegó a tener odio de Alcolea del Campo, así como un sentimiento de desaire e indiferencia.

Por no haber aguantado esa vida bucólica, aburrida y sin sentido del campo, decide renunciar a su trabajo y regresar a Madrid. La experiencia en Alcolea del Campo había terminado. Ya no podía vivir entre la gente del pueblo, ni intentar vivir en este ámbito insólito, donde los días pasaban sin ninguna emoción. Estaba seguro de que nada cambiaría, regresando, por lo tanto, a la ciudad "En el tren su estado nervioso empeoró. Se sentía desfallecido, mareado. Al llegar a Aranjuez se decidió a bajar del tren. Los tres días que pasó aquí tranquilizaron y calmaron sus nervios" (BAROJA, 1911, p. 231). Se observa, por lo tanto, que, a su regreso, se liberta. Su estadía en Alcolea del Campo le provocó, incluso, problemas de salud, tanto físicos como mental. Ya no volverá al pueblo.

\section{IV - Conclusión}

It is easy to separate the country and the city and then their modes of literature: the rural or regional; the urban or metropolitan. The existence of just these separated modes, in the twentieth century, is significant in itself, as a way of responding to a connected history (WILLIAMS, 1973, p. 264).

En conclusión, hemos analizado la experiencia del protagonista Andrés Hurtado tanto en el espacio urbano (Madrid) como en el espacio rural (Alcolea del Campo). El espacio social en ambos entornos se diferencia el uno al otro. Mientras en la ciudad los lugares de encuentro suelen ser principalmente los cafés y la calle misma, en el campo hay la escasez de estos ámbitos de encuentro siendo una cultura individualista y completamente ajena al personaje. Por ende, se hace presente una identidad dicotómica entre estos dos 
entornos vividos por Hurtado. A través de la teoría de Lefebvre, conocimos la representación de los espacios: percibido vivido concebido, conectados a la obra de Baroja.

Dialogamos en este ensayo sobre la importancia del espacio en la vida del protagonista por medio de descripciones literarias de la obra de Baroja. Nuestro objetivo fue comparar y contrastar la ciudad y el campo en la España de fines del siglo XIX a través de la historia de Andrés Hurtado en El árbol de la Ciencia de Pío Baroja, enterándonos de cómo ambos entornos tuvieran una significativa importancia para el protagonista durante el tiempo que vivió en estos espacios. Madrid le trajo el deleite mientras Alcolea del Campo le trajo el tedio.

$\mathrm{Al}$ no acostumbrarse con la vida campesina, nuestro protagonista regresa a la capital, donde había vivido anteriormente. Testificamos por medio de la obra de Baroja, por ende, que el espacio físico y social pueden influir en las decisiones de los personajes. Sin embargo, no tratamos en este ensayo de analizar psicológicamente el protagonista de la obra, sino de conectar el espacio vivido, concebido y percibido por el personaje a sus acciones de acuerdo con las descripciones que la obra como arte nos proporciona, por ello, consideramos a Andrés Hurtado un producto de su medio: social, cultural y primordialmente en este ensayo, espacial.

\section{ALCOLEA DEL CAMPO X MADRID: ANDRÉS HURTADO E O ESPAÇO SOCIAL NA OBRA "EL ÁRBOL DE LA CIENCIA" DE PÍO BAROJA}

RESUMO: El árbol de la ciencia é uma obra publicada por Pío Baroja em 1911. Esta pesquisa visa comparar e contrastar o espaço urbano da capital Madrid com o espaço rural em Alcolea del Campo através do texto literário de Baroja e seu protagonista: Andrés Hurtado. Através da teoria urbana de Henri Lefebvre e da teoria do campo e da cidade de Raymond Williams, se abordará neste ensaio perspectivas culturais, paisagens e representações sociais que são fundamentais para nossa análise de estilo e trabalho como arte. Se perceberá que a cidade é para Andrés Hurtado um ambiente cheio de vida, onde o urbano lhe proporciona prazer, enquanto o povoado lhe parece chato devido ao desempenho monótono dos indivíduos que lá residem. A paisagem também estará envolvida como parte desses espaços, sejam eles espaços de prazer ou desconsolo.

PALAVRAS-CHAVE: Espaço Social; Existencialismo; Literatura Española; Pío Baroja 


\section{REFERENCIAS}

AGULLÓ, Eva Ortz. Personaje y espacio urbano en la narrativa de Pio Baroja. 2016. 270 f. Tese (Doutorado) - Curso de Ciencias del Lenguaje, Ciencias del Lenguaje, Universidad de Córdoba, Córdoba, 2015. Disponível em: <helvia.uco.es/bitstream/handle/10396/13224 /2016000001288.pdf?sequence $=3 \&$ is Allowed $=y>$. Acesso em: 15 nov. 2017.

BAROJA, Pío. El árbol de la ciencia. Madrid: Caro Raggio / Cátedra, 2000.

Desde la Última Vuelta del Camino. Madrid: Editorial Caro Raggio, 1983.

BRIGGS, Ronald. An expansive and renewed costumbrismo. A Contra Corriente, Raleigh, v. 3, n. 13, p.331-335, 2016. Disponível em: <acontracorriente.chass.ncsu.edu/index.php/acontracorriente/article/view/1553/2719>. Acesso em: 25 nov. 2017.

EZQUERRA, David Baringo. La tesis de la producción del espacio en Henri Lefebvre y sus críticos: Un enfoque a tomar en consideración. Quid 16, Buenos Aires, n. 3, p.119-135, 2014. Disponível em: <publicaciones.sociales.uba.ar/index.php/quid16/article/view/1133>. Acesso em: 23 nov. 2017.

GARCÍA, Francisco Fuster. Campo y ciudad en la España de fin de siglo: una lectura simmeliana de El árbol de la ciencia (1911) de Pío Baroja. Arbor, [s.l.], v. 189, n. 761, p.1-10, 30 jun. 2013. Departmento de Publicaciones del CSIC. http://dx.doi.org/10.3989/arbor.2013.761n 3012 .

LEFEBVRE, Henri. La produción del espacio. Madrid: Capitán Swing, 2013. 468 p. Tradução de Emílio Martinez Gutiérrez.

MARTÍN, Esther Blanco. La literatura como recurso turístico: Los cafés literarios de Madrid. 2014. 57 f. TCC (Graduação) - Curso de Turismo, Universidade de Valladolid, Valladolid, 2014. Disponível em: <http://uvadoc.uva.es/bitstream/10324/5451/1/TFG-N.11.pdf>. Acesso em: 20 nov. 2017.

MASSAGLI, Sérgio Roberto. A Escrita como Lugar da Cidade: Ensaios sobre a apreensão e a representação do Espaço Urbano na Literatura. Jundiaí: Paco Editorial, 2015.

PETIT, Bruno Cruz. Las relaciones entre sociedad, espacio y medio ambiente en las distintas conceptualizaciones de la ciudad. Estudios Demográficos y Urbanos, Pedregal, v. 1, n. 29, p.183-205, 2014. Disponível em: <http://www.scielo.org.mx/scielo.php?script=sci_arttext\&pid=S0186-72102014000100183>. Acesso em: 18 nov. 2017.

RICCI, Cristián Horacio. Madrid en el Discurso Narrativo de los Modernistas Españoles (19011912). 2003. 333 f. Tese (Doutorado) - Curso de Hispanic Languages And Literature, Universidade da California, Santa Barbara, 2003.

RAMINELLI, Ronald. O campo e a cidade na história e na literatura. Revista de História, São Paulo, n. 122, p.171-174, 1990. Disponível em: <www.revistas.usp.br/revhistoria/article/view/64293.>. Acesso em: 21 nov. 2017. 
RODRIGUES, Susana Cristina Caleiro. Ignis elementatus: o fogo como centro e simbolo da casa. 2015. 189 f. Dissertação (Mestrado) - Curso de Mestrado Integrado em Arquitectura, Departamento de Arquitectura, Universidade de Évora, Évora, 2015.

SILVA, Sofia Rosas da. Sentimento de Comunidade e Bem-Estar em Contexto Institucional: Perceção das Pessoas Idosas. Exedra Revista Cientifica, Coimbra, p.29-46, 2015.

WILLIAMS, Raymond. El campo y la ciudad. Buenos Aires: Paidós, 2001. 411 p. Tradução de Alcira Bixio.

. The country and the city. New York: University Press, 1973.

ZWEIG, Stefan. Tres maestros: Balzac, Dickens, Dostoievski. Barcelona: El Acantilado, 2004. $232 \mathrm{p}$.

Recebido em: 22/05/2018. Aprovado em: 16/07/2018. 